\title{
FIXED POINTS FOR TRIANGULAR $\alpha$-ADMISSIBLE GERAGHTY CONTRACTION TYPE MAPPINGS IN PARTIAL $b$-METRIC SPACES
}

\section{HAITHAM QAWAQNEH ${ }^{1, *}$, MOHD SALMI NOORANI ${ }^{1}$, WASFI SHATANAWI ${ }^{2,3}$ AND HABES ALSAMIR ${ }^{1}$}

${ }^{1}$ School of mathematical Sciences, Faculty of Science and Technology, Universiti Kebangsaan Malaysia, 43600 UKM, Selangor Darul Ehsan, Malaysia

${ }^{2}$ Department of Mathematics and General Courses, Prince Sultan University, Riyadh 11586, Saudi Arabia

${ }^{3}$ Department of Medical Research, China Medical University Hospital, China Medical University, Taichung 40402, Taiwan

*Corresponding author: Haitham.math77@gmail.com

\begin{abstract}
In this paper, we introduce the notion of generalized $C$-class functions for Geraghty contraction type mappings on a set $X$. We utilize our new notion to prove fixed point results in the setting of triangular weak $\alpha$-admissible mappings with respect to $\eta$ in Partial $b$-Metric Spaces. Our results modify and improve many exciting results in the literature. Also, we introduce an example and an application to show the validity of our main result.
\end{abstract}

Received 2018-09-26; accepted 2018-11-20; published 2019-03-01.

2010 Mathematics Subject Classification. 47H10, 54H25.

Key words and phrases. C-class functions; $\alpha$-admissible mapping; fixed point; $b$-metric spaces; partial metric spaces; partial $b$-metric spaces.

(C)2019 Authors retain the copyrights of their papers, and all open access articles are distributed under the terms of the Creative Commons Attribution License. 


\section{INTRODUCTION AND PRELIMINARIES}

One of the most important tools in fixed point theory is Banach contraction principle. A lot of authors have extended or generalized this contraction and proved the existence of fixed and common fixed point theorems (for example see [19]- [28]). In this sequel, Bakhtin [7] and Czerwik [10] introduced b-metric spaces as a generalization of metric spaces. They proved the contraction mapping principle in $b$-metric spaces that generalized the famous Banach contraction principle in such spaces. After that, several papers have dealt with fixed point theory for single-valued and multi-valued operators in b-metric spaces (for example see [11], [27], [29], [32]).

On the other hand, Matthews [21] introduced the notion of partial metric space as a part of the study of denotational semantics of dataflow networks, showing that the contraction mapping principle [8] can be generalized to the partial metric context for applications in program verifications.

$b$-metric spaces [7] and Partial metric spaces [21] are two well known generalizations of usual metric spaces. Also, the Banach contraction principle is a fundamental result in the fixed point theory, which has been used and extended in many different directions. Recently, Shukla [35] introduced a generalization and unification of partial metric and b-metric spaces as the concept of partial b-metric space.

In this section, we recall some useful definitions and auxiliary results that will be needed in the sequel. Throughout this paper, $\mathbb{N}$ and $\mathbb{R}$ denote the set of natural numbers and the set of real numbers, respectively.

Definition 1.1. ( [7], [10]) Let $X$ is a nonempty set and let $s \geq 1$ be a given real number. A function $d: X \times X \rightarrow[0, \infty)$ is said to be a b-metric space on $X$ if and only if for all $x, y, z \in X$, the following conditions hold:

(1) $d(x, y)=0$ if and only if $x=y$,

(2) $d(x, y)=d(y, x)$,

(3) $d(x, z) \leq s[d(x, y)+d(y, z)]$.

The triplet $(X, d, s)$ is called a $b$-metric space.

It is well known that the class of b-metric spaces is larger than the class of metric spaces when $s=1$, the concept of b-metric space coincides with the concept of metric space.

Example 1.1. Consider the set $X=[0,1]$ endowed with the function $d: X \times X \rightarrow[0, \infty)$ defined by $d(x, y)=|x-y|^{2}$ for all $x, y \in X$. Clearly, $(X, d, 3)$ is a b-metric space but it is not a metric space. 
Example 1.2. Let $X=\mathbb{R}$ and let the mapping $d: X \times X \rightarrow[0, \infty)$ be defined by

$$
d(x, y)=|x-y|^{2} \text { for all } x, y \in X
$$

Then $(X, d)$ is a b-metric space with coefficient $s=2$.

Definition 1.2. [21] Let $X$ be a nonempty set. A function $p: X \times X \rightarrow[0, \infty)$ is called a partial metric space if for all $x, y, z \in X$, the following conditions are satisfied:

$\left(p_{1}\right) x=y \Leftrightarrow p(x, x)=p(x, y)=p(y, y)$,

$\left(p_{2}\right) p(x, x) \leq p(x, y)$,

$\left(p_{3}\right) p(x, y)=p(y, x)$,

$\left(p_{4}\right) p(x, y) \leq p(x, z)+p(z, y)-p(z, z)$.

The pair $(X, p)$ is called a partial metric space(PMS). The sequence $\left\{x_{n}\right\}$ in $X$ converges to a point $x \in X$ if $\lim _{n \rightarrow \infty} p\left(x_{n}, x\right)=p(x, x)$. Also the sequence $\left\{x_{n}\right\}$ is called $p$-Cauchy if the $\lim _{n, m \rightarrow \infty} p\left(x_{n}, y_{m}\right)$ exists. The partial metric space $(X, p)$ is called complete if for every $p$-Cauchy sequence $\left\{x_{n}\right\}_{\infty}^{n}$, there is some $x \in X$ such that

$$
p(x, x)=\lim _{n \rightarrow \infty} p\left(x_{n}, x\right)=\lim _{n, m \rightarrow \infty} p\left(x_{n}, x_{m}\right)
$$

A basic example of a partial metric space is the pair $\left(\mathbb{R}^{+}, p\right)$, where $p(x, y)=\max \{x, y\}$ for all $x, y \in \mathbb{R}^{+}$.

Definition 1.3. [35] Let $X$ be a nonempty set. A function $b: X \times X \rightarrow[0, \infty)$ is called a b-partial metric space if for all $x, y, z \in X$, the following conditions are satisfied:

$\left(p_{b 1}\right) x=y$ if and only if $b(x, x)=b(x, y)=b(y, y)$,

$\left(p_{b 2}\right) b(x, x) \leq b(x, y)$,

$\left(p_{b 3}\right) b(x, y)=b(y, x)$

$\left(p_{b 4}\right)$ there exists a real number $s \geq 1$ such that $b(x, y) \leq s[b(x, z)+b(z, y)]-b(z, z)$.

Remark 1.1. [35] In a partial b-metric space $(X, b)$ if $x, y \in X$ and $b(x, y)=0$, then $x=y$, but the converse may not be true.

Remark 1.2. [35] It is clear that every partial metric space is a partial b-metric space with coefficient $s=1$ and every $b$-metric space is a partial b-metric space with the same coefficient and zero self-distance. However, the converse of this fact need not hold.

Example 1.3. [35] Let $X=\mathbb{R}^{+}, p>1$ is a constant and $b: X \times X \rightarrow \mathbb{R}^{+}$be defined by

$$
b(x, y)=[\max \{x, y\}]^{p}-|x-y|^{p}
$$


for all $x, y \in X$. Then, $(X, b)$ is a partial $b$-metric space with coefficient $s=2 p>1$, but it is neither a b-metric nor a partial metric space.

Proposition 1.1. [35] Let $X$ be a nonempty set such that $p$ is a partial and $d$ is a b-metric with coefficient $s>1$ on $X$. Then the function $b: X \times X \rightarrow \mathbb{R}^{+}$defined by $b(x, y)=p(x, y)+d(x, y)$ for all $x, y \in X$ is a partial b-metric on $X$, that is, $(X, b)$ is a partial b-metric space.

Definition 1.4. [35] Let $(X, b)$ be be a partial b-metric space with coefficient s. Let $\left\{x_{n}\right\}$ be any sequence in $X$ and $x \in X$. Then:

(i) A sequence $\left\{x_{n}\right\} \subseteq X$ converges to a point $x \in X$ if $\lim _{n \rightarrow \infty} b\left(x_{n}, x\right)=b(x, x)$,

(ii) A sequence $\left\{x_{n}\right\} \subseteq X$ is said to be a Cauchy sequence in $(X, b)$ if, for every given $\epsilon>0$, there exists $n(\epsilon) \in \mathbb{N}$ such that $\lim _{n, m \rightarrow \infty} b\left(x_{n}, x_{m}\right)$ exists and is finite for all $m, n \geq n(\epsilon)$,

(iii) $(X, b)$ is said to be complete partial b-metric space if Cauchy sequence $\left\{x_{n}\right\} \subseteq X$ there exists $x \in X$ such that

$$
\lim _{n, m \rightarrow \infty} b\left(x_{n}, x_{m}\right)=\lim _{n \rightarrow \infty} b\left(x_{n}, x\right)=b(x, x) .
$$

Note that in a partial $b$-metric space the limit of convergent sequence may not be unique.

Samet el al. [31] introduced the notion of $\alpha$-admossible mapping and studied many fixed point theorems. After that several authors used the notion of $\alpha$-admissible to prove and construct many fixed and common fixed point theorems (see [14]- [1]).

Samet et al. [31] presented the notion of $\alpha$-admissible mapping as follows:

Definition 1.5. [31] Let $f: X \rightarrow X$ and $\alpha: X \times X \rightarrow[0, \infty)$. Then $f$ is called $\alpha$-admissible if $\forall x, y \in X$ with $\alpha(x, y) \geq 1$ implies $\alpha(f x, f y) \geq 1$.

Definition 1.6. [17] Let $T: X \rightarrow X$ and $\alpha: X \times X \rightarrow[0, \infty)$. Then $T$ is called a triangular $\alpha$-admissible mapping if

(1) $T$ is $\alpha$-admissible;

(2) $\alpha(x, z) \geq 1$ and $\alpha(z, y) \geq 1$ imply $\alpha(x, y) \geq 1$.

Sintunavarat [32] presented the notion of weak $\alpha$-admissible mappings as follows:

Definition 1.7. [32] Let $X$ be a nonempty set and let $\alpha: X \times X \rightarrow[0, \infty)$ be a given mapping. A mapping $f: X \rightarrow X$ is said to be a weak $\alpha$-admissible mappings if the following condition holds:

$$
x \in X \text { with } \alpha(x, f x) \geq 1 \Rightarrow \alpha\left(f x, f^{2} x\right) \geq 1
$$


Remark 1.3. [32] It is customary to write $\mathcal{A}(X, \alpha)$ and $\mathcal{W} \mathcal{A}(X, \alpha)$ to denote the collection of all $\alpha$ admissible mappings on $X$ and the collection of all weak $\alpha$-admissible mappings on $X$. One can verify that $\mathcal{A}(X, \alpha) \subseteq \mathcal{W} \mathcal{A}(X, \alpha)$

Qawaqneh et al. [23] presented the notion of $\alpha$-admissible with respect to another function $\eta$ for the pair of self-mappings $S$ and $T$ on a set $X$ as follows:

Definition 1.8 ( [23]). Let $S, T: X \rightarrow X$ be two mappings and $\alpha: X \times X \rightarrow[0,+\infty)$ be a function such that the following conditions hold:

(1) if $\alpha(x, y) \geq 1$, then $\alpha(S x, T y) \geq 1$ and $\alpha(T S x, S T y) \geq 1$;

(2) if $\alpha(x, z) \geq 1$ and $\alpha(z, y) \geq 1$, then $\alpha(x, y) \geq 1$.

Then we say that the pair $(S, T)$ is triangular $\alpha$-admissible.

Definition 1.9 ( [23]). Let $S, T: X \rightarrow X$ be two mappings and $\alpha, \eta: X \times X \rightarrow[0,+\infty)$ be two functions such that the following conditions hold:

(1) if $\alpha(x, y) \geq \eta(x, y)$, then $\alpha(S x, T y) \geq \eta(S x, T y)$ and $\alpha(T S x, S T y) \geq \eta(T S x, S T y)$;

(2) if $\alpha(x, z) \geq \eta(x, z)$ and $\alpha(z, y) \geq \eta(z, y)$, then $\alpha(x, y) \geq \eta(x, y)$.

Then we say that the pair $(S, T)$ is triangular $\alpha$-admissible with respect to $\eta$.

Lemma 1.1 ( [23]). Let $S, T: X \rightarrow X$ be two mappings and $\alpha, \eta: X \times X \rightarrow[0,+\infty)$ be two functions such that the pair $(S, T)$ is triangular $\alpha$-admissible with respect to $\eta$. Assume that there exists $x_{0} \in X$ such that $\alpha\left(x_{0}, S x_{0}\right) \geq \eta\left(x_{0}, S x_{0}\right)$. Define a sequence $\left\{x_{n}\right\}$ in $X$ by $S x_{2 n}=x_{2 n+1}$ and $T x_{2 n+1}=x_{2 n+2}$. Then $\alpha\left(x_{n}, x_{m}\right) \geq \eta\left(x_{n}, S x_{m}\right)$ for all $m, n \in \mathbb{N}$ with $n<m$.

In 2014, Ansari [4] defined the concept of C-class function as the following:

Definition 1.10. [4] A mapping $F: \mathbb{R}^{+} \times \mathbb{R}^{+} \rightarrow \mathbb{R}$ is called a $C$-class function if it is continuous and for $s, t \in[0, \infty), F$ satisfies the following two conditions:

(1) $F(s, t) \leq s$; and

(2) $F(s, t)=s$ implies that either $s=0$ ort $=0$.

The family of all $C$-class functions is denoted by $\mathcal{C}$.

Example 1.4. [4] The following functions $F: \mathbb{R}^{+} \times \mathbb{R}^{+} \rightarrow \mathbb{R}$ are elements in $\mathcal{C}$.

(1) $F(s, t)=s-t$ for all $s, t \in[0, \infty)$.

(2) $F(s, t)=k s$ for all $s, t \in[0, \infty)$, where $0<k<1$.

(3) $F(s, t)=\frac{s}{(1+t)^{r}}$ for all $s, t \in[0, \infty)$, where $r \in[0, \infty)$.

(4) $F(s, t)=(s+l)^{\left(1 /(1+t)^{r}\right)}-l$ for all $s, t \in[0, \infty)$, where $r \in(0, \infty), l>1$. 
(5) $F(s, t)=s \log _{t+a}$ a for all $s, t \in[0, \infty)$, where $a>1$.

(6) $F(s, t)=s-\left(\frac{1+s}{2+s}\right)\left(\frac{t}{1+t}\right)$ for all $s, t \in[0, \infty)$.

(7) $F(s, t)=s \beta(s)$ for all $s, t \in[0, \infty)$, where $\beta:[0, \infty) \rightarrow[0,1)$ is continuous.

(8) $F(s, t)=s-\varphi(s)$ for all $s, t \in[0, \infty)$, where $\varphi:[0, \infty) \rightarrow[0, \infty)$ is a continuous function such that $\varphi(t)=0$ if and only if $t=0$.

(9) $F(s, t)=\operatorname{sh}(s, t)$ for all $s, t \in[0, \infty)$, where $h:[0, \infty) \rightarrow[0, \infty)$ is a continuous function such that $h(s, t)<1$ for all $s, t \in[0, \infty)$.

(10) $F(s, t)=s-\left(\frac{2+t}{1+t}\right) t$ for all $s, t \in[0, \infty)$.

(11) $F(s, t)=\sqrt[n]{\ln \left(1+s^{n}\right)}$ for all $s, t \in[0, \infty)$.

In 2016, Ansari and Kaewcharoen [6] gave the definition of a generalized $\alpha-\eta-\psi-\varphi-F$-contraction type mapping and proved same fixed point theorems for such mappings in complete metric spaces.

Definition $1.11([6])$. Let $(X, d)$ be a metric space and $\alpha, \eta: X \times X \rightarrow[0, \infty)$ be two functions. A mapping $T: X \rightarrow X$ is said to be a generalized $\alpha-\eta-\psi-\varphi-F$-contraction type mapping if $\alpha(x, y) \geq \eta(x, y)$ implies

$$
\psi(d(T x, T y)) \leq F(\psi(M(x, y)), \varphi(M(x, y)))
$$

where

$$
M(x, y)=\max \{d(x, y), d(x, T x), d(y, T y)\}
$$

Hussain et al. [15] introduced the concepts of $\alpha-\eta$-complete metric spaces and $\alpha-\eta$-continuous functions.

Definition 1.12 ( [15]). Let $(X, d)$ be a metric space and $\alpha, \eta: X \times X \rightarrow[0, \infty)$ be two functions. Then $X$ is said to be an $\alpha, \eta$-complete metric space if every Cauchy sequence $\left\{x_{n}\right\}$ in $X$ with $\alpha\left(x_{n}, x_{n+1}\right) \geq \eta\left(x_{n}, x_{n+1}\right)$ for all $n \in \mathbb{N}$ converges in $X$.

Definition 1.13 ( $[15])$. Let $(X, d)$ be a metric space and $\alpha, \eta: X \times X \rightarrow[0, \infty)$ be two functions. $A$ mapping $T: X \rightarrow X$ is said to be an $\alpha, \eta$-continuous mapping if each sequence $\left\{x_{n}\right\}$ in $X$ with $x_{n} \rightarrow x$ as $n \rightarrow \infty$ and $\alpha\left(x_{n}, x_{n+1}\right) \geq \eta\left(x_{n}, x_{n+1}\right)$ for all $n \in \mathbb{N}$ implies $T x_{n} \rightarrow$ Tx as $n \rightarrow \infty$.

Theorem $1.1([6])$. Let $(X, d)$ be a metric space. Assume that $\alpha, \eta: X \times X \rightarrow[0, \infty)$ are two functions and $T: X \rightarrow X$ is a mapping. Suppose that the following conditions are satisfied:

(1) $(X, d)$ is an $\alpha, \eta$-complete metric space;

(2) $T$ is generalized $\alpha-\eta-\psi-\varphi-F$-contraction type mapping;

(3) $T$ is triangular $\alpha$-orbital admissible mapping with respect to $\eta$;

(4) there exists $x_{1} \in X$ such that $\alpha\left(x_{1}, T x_{1}\right) \geq \eta\left(x_{1}, T x_{1}\right)$;

(5) $T$ is an $\alpha, \eta$-continuous mapping. 
Then $T$ has a fixed point $x^{*} \in X$.

Khan et al. [20] introduced the notion of an altering distance function as follows:

Definition 1.14. [20] A mapping $\psi: \mathbb{R}^{+} \rightarrow \mathbb{R}^{+}$is called an altering distance function if the following properties are satisfied:

(1) $\psi$ is monotone and nondecreasing;

(2) $\psi(t)=0$ if an only if $t=0$.

The set of all altering distance functions is denoted by $\Psi$.

In the rest of this paper, we let $\phi$ be the set of all functions $\varphi: \mathbb{R}^{+} \rightarrow \mathbb{R}^{+}$such that

(1) $\varphi$ is continuous.

(2) $\varphi(t)=0$ if and only if $t=0$.

\section{MAIN RESULT}

In this section, we introduce the concept of generalized $C$-class functions for Geraghty contraction type mappings on a set $X$ and we prove fixed point results for self mappings on $\alpha, \eta-$ partial $b-$ metric space.

Now, we present the notion of triangular weak $\alpha$-admissible with respect to another function $\eta$ for the self-mapping $S$ on a set $X$.

Definition 2.1. Let $S: X \rightarrow X$ be a mapping and $\alpha, \eta: X \times X \rightarrow[0,+\infty)$ be two functions such that the following conditions hold:

(1) if $\alpha\left(x, S^{n} x\right) \geq \eta\left(x, S^{n} x\right)$, then $\alpha\left(S^{n} x, S^{n+1} x\right) \geq \eta\left(S^{n} x, S^{n+1} x\right)$,

(2) if $\alpha(x, z) \geq \eta(x, z)$ and $\alpha(z, y) \geq \eta(z, y)$, then $\alpha(x, y) \geq \eta(x, y)$,

for all $n \in \mathbb{N}$. Then we say that $S$ is triangular weak $\alpha$-admissible with respect to $\eta$.

Now, we introduce the following example to illustrate our new definition.

Example 2.1. Let $X=[0,+\infty)$. Define $S: X \rightarrow X$ by $S x=x^{2}$. Also, define the functions $\alpha, \eta: X \times X \rightarrow$ $[0,+\infty)$ by $\alpha(x, y)=e^{x+y}$ and $\eta(x, y)=e^{y-x}$. Then $S$ is triangular weak $\alpha$-admissible with respect to $\eta$.

Proof. If $\alpha(x, S x) \geq \eta(x, S x)$, then $e^{x+x^{2}} \geq e^{x^{2}-x}$. So $x+x^{2} \geq x^{2}-x$. So $2 x \geq 0$. Hence $x \geq 0$. Since $x \geq-x$, then $x+x^{4} \geq x^{4}-x$. So $e^{x+{ }^{4}} \geq e^{4}-x$. Hence $\alpha\left(x,{ }^{4}\right) \geq \eta\left(x,{ }^{4}\right)$. So $\alpha(S x, T y) \geq \eta(S x, T y)$. Also, since $x^{2} \geq-x^{2}$, then $x^{2}+y^{2} \geq y^{2}-x^{2}$. So $e^{x^{2}+y^{2}} \geq e^{y^{2}-x^{2}}$. Hence $\alpha\left(x^{2}, y^{2}\right) \geq \eta\left(x^{2}, y^{2}\right)$. So $\alpha\left(S x, S^{2} x\right) \geq \eta\left(S x, S^{2} x\right)$. Also, if $\alpha(x, z) \geq \eta(x, z)$, and $\alpha(z, y) \geq \eta(z, y)$, then $x+z \geq z-x$ and $z+y \geq y-z$. So $x \geq-x$ and hence $x+x^{2} \geq x^{2}-x$. Therefore $e^{x+y} \geq e^{y-x}$. Therefore $\alpha(x, S x) \geq \eta(x, S x)$. 
By taking a special case of Lemma 1.1and generalize with is triangular weak $\alpha$-admissible with respect to $\eta$, we present a lemma that will be helpful for us to achieve our main result.

Lemma 2.1. Let $S: X \rightarrow X$ be a mappings and $\alpha, \eta: X \times X \rightarrow \mathbb{R}$ are a functions such that $S$ is triangular weak $\alpha$-admissible with respect to $\eta$. Assume that there exist $x_{0} \in X$ such that $\alpha\left(x_{0}, S x_{0}\right) \geq \eta\left(x_{0}, S x_{0}\right)$. Define a sequence $\left\{x_{n}\right\}$ in $X$ by $S x_{n}=x_{n+1}$. Then $\alpha\left(x_{n}, x_{m}\right) \geq \eta\left(x_{n}, x_{m}\right)$ for all $m, n \in \mathbb{N}$ with $n<m$.

Proof. Since $\alpha\left(x_{0}, S x_{0}\right) \geq \eta\left(x_{0}, S x_{0}\right)$ and $S$ is weak $\alpha$-admissible, We get

$$
\left\{\begin{array}{l}
\alpha\left(x_{0}, x_{1}\right)=\alpha\left(x_{0}, S x_{0}\right) \geq \eta\left(x_{0}, x_{1}\right), \text { then } \\
\alpha\left(S x_{0}, S x_{1}\right)=\alpha\left(S x_{0}, S^{2} x_{0}\right)=\alpha\left(x_{1}, x_{2}\right) \geq \eta\left(x_{1}, x_{2}\right) .
\end{array}\right.
$$

By triangular $\alpha$-admissibility, we get

$$
\left\{\begin{array}{l}
\alpha\left(S x_{0}, S x_{1}\right)=\alpha\left(x_{1}, x_{2}\right) \geq \eta\left(x_{1}, x_{2}\right), \text { then } \\
\alpha\left(S^{2} x_{0}, S^{2} x_{1}\right)=\alpha\left(x_{2}, x_{3}\right) \geq \eta\left(x_{2}, x_{3}\right)
\end{array}\right.
$$

and

$$
\alpha\left(S^{2} x_{1}, S^{2} x_{2}\right)=\alpha\left(x_{3}, x_{4}\right) \geq \eta\left(x_{3}, x_{4}\right)
$$

Again, since $\alpha\left(x_{3}, x_{4}\right) \geq \eta\left(x_{3}, x_{4}\right)$, then

$$
\alpha\left(S^{2} x_{3}, S^{2} x_{4}\right)=\alpha\left(x_{4}, x_{5}\right) \geq \eta\left(x_{4}, x_{5}\right)
$$

and

$$
\alpha\left(S^{2} x_{4}, S^{2} x_{5}\right)=\alpha\left(x_{5}, x_{6}\right) \geq \eta\left(x_{5}, x_{6}\right)
$$

By continuing the above process, we conclude that $\alpha\left(x_{n}, x_{n+1}\right) \geq \eta\left(x_{n}, x_{n+1}\right)$ for all $n \in \mathbb{N} \cup\{0\}$.

Now, we prove that

$\alpha\left(x_{n}, x_{m}\right) \geq 1, \forall m, n \in \mathbb{N}$ with $n<m$.

Given $m, n \in \mathbb{N}$ with $n<m$. Since

$$
\left\{\begin{array}{l}
\alpha\left(x_{n}, x_{n+1}\right) \geq \eta\left(x_{n}, x_{n+1}\right) \\
\alpha\left(S x_{n}, S^{2} x_{n}\right)=\alpha\left(x_{n+1}, x_{n+2}\right) \geq \eta\left(x_{n+1}, x_{n+2}\right),
\end{array}\right.
$$

then, we have

$$
\alpha\left(x_{n}, x_{n+2}\right) \geq \eta\left(x_{n}, x_{n+2}\right)
$$

Again, since

$$
\left\{\begin{array}{l}
\alpha\left(x_{n}, x_{n+2}\right) \geq \eta\left(x_{n}, x_{n+2}\right) \\
\alpha\left(S x_{n+1}, S^{2} x_{n+1}\right)=\alpha\left(x_{n+2}, x_{n+3}\right) \geq \eta\left(x_{n+2}, x_{n+3}\right),
\end{array}\right.
$$

we deduce that

$$
\alpha\left(x_{n}, x_{n+3}\right) \geq \eta\left(x_{n}, x_{n+3}\right)
$$


By continuing this process, we have

$$
\alpha\left(x_{n}, x_{m}\right) \geq \eta\left(x_{n}, x_{m}\right)
$$

for all $n \in \mathbb{N}$ with $m>n$.

In order to facilitate our subsequent arguments, we introduce the notion of generalized $C$-class functions for self mappings on a set $X$.

Definition 2.2. Let $(X, b)$ be a complete $b$-partial metric space with coefficient $s \geq 1, S: X \rightarrow X$ be a Geraghty contraction type mapping and $\alpha, \eta: X \times X \rightarrow \mathbb{R}$ be a function. Let $F \in \mathcal{C}, \psi \in \Psi$ and $\varphi \in \Phi$. Then $S$ is called generalized $C$-class function with $\alpha(x, y) \geq \eta(x, y)$, then

$$
\psi(b(S x, S y)) \leq \lambda F(\psi(M(x, y)), \varphi(M(x, y)))
$$

where

$$
M(x, y)=\max \left\{b(x, y), b(x, S x), b(y, S y), \frac{b(x, S y)+b(y, S x)}{2}\right\}
$$

and $\lambda \in\left[0, \frac{1}{s}\right)$.

Theorem 2.1. Let $(X, b)$ be a complete $b$-partial metric space with coefficient $s \geq 1$ and $S$ be Geraghty contraction type mapping on $X$. Assume that $\alpha, \eta: X \times X \rightarrow[0,+\infty)$ are a functions. Suppose that the following conditions hold:

(1) $S$ is generalized $C$-class function.

(2) $S$ is a triangular weak $\alpha$-admissible.

(3) There exists $x_{0} \in X$ such that $\alpha\left(x_{0}, S x_{0}\right) \geq 1$.

(4) $S$ is $\alpha, \eta$-continuous mappings.

Then $S$ has a unique fixed point.

Proof. We divide the proof to three steps:

Step 1. Let $x_{0} \in X$ be such that $\alpha\left(x_{0}, S x_{0}\right) \geq \eta\left(x_{0}, S x_{0}\right)$. Define a sequence $\left\{x_{n}\right\}$ in $X$ such that $x_{n+1}=S x_{n}$ for all $n \in \mathbb{N}$. If $x_{n_{0}}=x_{n_{0}+1}$ for some $n_{0} \in \mathbb{N}$, then it is very easy to show that $S$ has a fixed point. Now, since the pair $S$ is $\alpha$-admissible, then

$$
\alpha\left(x_{1}, x_{2}\right)=\alpha\left(S x_{0}, S^{2} x_{0}\right) \geq \eta\left(x_{1}, x_{2}\right)
$$

and

$$
\alpha\left(x_{2}, x_{3}\right)=\alpha\left(S x_{1}, S^{2} x_{1}\right) \geq \eta\left(x_{2}, x_{3}\right) .
$$


Again, by using the property of weak $\alpha$-admissible and repeating the above process for $n$-times, we have $\alpha\left(x_{n}, x_{n+1}\right) \geq \eta\left(x_{n}, x_{n+1}\right)$ and $\alpha\left(x_{n+1}, x_{n}\right) \geq \eta\left(x_{n+1}, x_{n}\right)$.

Using the property of triangular weak $\alpha$-admissible, we can deduce that for any $n, m \in \mathbb{N}$ with $m>n$, we have $\alpha\left(x_{n}, x_{m}\right) \geq \eta\left(x_{n}, x_{m}\right)$ and $\alpha\left(x_{m}, x_{n}\right) \geq \eta\left(x_{m}, x_{n}\right)$.

Suppose $x_{n} \neq x_{n+1}$ for all $n \in \mathbb{N}$, by Lemma 2.1, we have $\alpha\left(x_{n}, x_{n+1}\right) \geq \eta\left(x_{n}, x_{n+1}\right)$ for all $n \in \mathbb{N}$. Since $S$ is a generalized $C$-class function, we have

$$
\begin{aligned}
\psi\left(b\left(x_{n+1}, x_{n}\right)\right) & =\psi\left(b\left(S x_{n}, S x_{n-1}\right)\right) \\
& \leq \lambda F\left(\psi\left(M\left(x_{n}, x_{n-1}\right)\right), \varphi\left(M\left(x_{n}, x_{n-1}\right)\right)\right) \\
& \leq \lambda \psi\left(M\left(x_{n}, x_{n-1}\right)\right)
\end{aligned}
$$

for all $n \in \mathbb{N}$, where

$$
\begin{aligned}
M\left(x_{n}, x_{n-1}\right) & =\max \left\{b\left(x_{n}, x_{n-1}\right), b\left(x_{n}, S x_{n}\right), b\left(x_{n-1}, S x_{n-1}\right), \frac{b\left(x_{n}, S x_{n-1}\right)+b\left(x_{n-1}, S x_{n}\right)}{2}\right\} \\
& =\max \left\{b\left(x_{n}, x_{n-1}\right), b\left(x_{n}, x_{n+1}\right), b\left(x_{n-1}, x_{n}\right), \frac{b\left(x_{n}, x_{n}\right)+b\left(x_{n-1}, x_{n+1}\right)}{2}\right\} \\
& =\max \left\{b\left(x_{n}, x_{n-1}\right), b\left(x_{n}, x_{n+1}\right)\right\}
\end{aligned}
$$

If $M\left(x_{n}, x_{n-1}\right)=b\left(x_{n}, x_{n+1}\right)$, then

$$
\begin{aligned}
\psi\left(b\left(x_{n+1}, x_{n}\right)\right) & \leq \lambda F\left(\psi\left(M\left(x_{n}, x_{n-1}\right), \varphi\left(M\left(x_{n}, x_{n-1}\right)\right)\right)\right. \\
& \leq \lambda \psi\left(M\left(x_{n}, x_{n-1}\right)\right) \\
& =\lambda \psi\left(b\left(x_{n+1}, x_{n}\right)\right) \\
& <\psi\left(b\left(x_{n+1}, x_{n}\right)\right) .
\end{aligned}
$$

Which is contraction. Thus we conclude that $M\left(x_{n}, x_{n-1}\right)=b\left(x_{n}, x_{n-1}\right)$. By $(2.2)$, we get that

$$
\psi\left(b\left(x_{n+1}, x_{n}\right)\right) \leq \lambda \psi\left(b\left(x_{n}, x_{n-1}\right)\right)
$$

for all $n \in \mathbb{N}$.

On repeating this process, we obtain

$$
\psi\left(b\left(x_{n+1}, x_{n}\right)\right) \leq \lambda^{n} \psi\left(b\left(x_{1}, x_{0}\right)\right)
$$

for all $n>0$.

Since $\psi$ is nondecreasing, we have $b\left(x_{n+1}, x_{n+2}\right) \leq b\left(x_{n}, x_{n+1}\right)$ for all $n \in \mathbb{N}$.

Similarly, we can show that $b\left(x_{n}, x_{n+1}\right) \leq b\left(x_{n-1}, x_{n}\right)$.

for all $n \in \mathbb{N} \cup\{0\}$.

It follow that the sequence $\left\{b\left(x_{n}, x_{n+1}\right)\right\}$ is nonincreasing for all $n \in \mathbb{N}$. Therefore there exists $r \geq 0$ such 
that $\lim _{n \rightarrow \infty} b\left(x_{n}, x_{n+1}\right)=r$. We claim that $r=0$.

Now, we have

$$
\psi\left(b\left(x_{n+1}, x_{n+2}\right)\right) \leq \lambda F\left(\psi\left(b\left(x_{n}, x_{n+1}\right)\right), \varphi\left(b\left(x_{n}, x_{n+1}\right)\right)\right)<F\left(\psi\left(b\left(x_{n}, x_{n+1}\right)\right), \varphi\left(b\left(x_{n}, x_{n+1}\right)\right)\right) .
$$

Taking $n \rightarrow \infty$, we obtain that

$$
\psi(r) \leq \lambda F(\psi(r), \varphi(r))<F(\psi(r), \varphi(r))
$$

This implies that $\psi(r)=0$ or $\varphi(r)=0$ which yields

$$
\lim _{n \rightarrow \infty} b\left(x_{n}, x_{n+1}\right)=0
$$

Step 2. To prove that $\left\{x_{n}\right\}$ is a Cauchy sequence, there exist $\epsilon>0$ and two subsequences $\left\{x_{m(k)}\right\}$ and $\left\{x_{n(k)}\right\}$ of $\left\{x_{n}\right\}$ with $m_{k}>n_{k}>k$ such that:

$$
d\left(x_{n(k)}, x_{m(k)}\right) \geq \epsilon, d\left(x_{n(k)}, x_{m(k)-1}\right)<\epsilon .
$$

Then, using the triangular inequality we get

$$
\begin{aligned}
b\left(x_{n}, x_{m(k)}\right) & \leq s\left[b\left(x_{n(k)}, x_{n(k)+1}\right)+b\left(x_{n(k)+1}, x_{m(k)}\right)\right]-b\left(x_{n(k)+1}, x_{n(k)+1}\right) \\
& \leq s b\left(x_{n(k)}, x_{n(k)+1}\right)+s^{2}\left[b\left(x_{n(k)+1}, x_{n(k)+2}\right)+b\left(x_{n(k)+2}, x_{m(k)}\right)-s b\left(x_{n(k)+2}, x_{n(k)+2}\right)\right. \\
& \leq s b\left(x_{n(k)}, x_{n(k)+1}\right)+s^{2} b\left(x_{n(k)+1}, x_{n(k)+2}\right)+s^{3} b\left(x_{n(k)+2}, x_{n(k)+2}\right)+\ldots+s^{m-n} b\left(x_{m(k)-1}, x_{m(k)}\right) .
\end{aligned}
$$

Using (2.6) in the above inequality

$$
\begin{aligned}
b\left(x_{n}, x_{m(k)}\right) & \leq s \lambda^{n} b\left(x_{1}, x_{0}\right)+s^{2} \lambda^{n+1} b\left(x_{1}, x_{0}\right)+s^{3} \lambda^{n+3} b\left(x_{1}, x_{0}\right)+\ldots+s^{m-n} \lambda^{m-1} b\left(x_{1}, x_{0}\right) \\
& \leq s \lambda^{n}\left[1+s \lambda+(s \lambda)^{2}+\ldots\right] b\left(x_{1}, x_{0}\right) \\
& =\frac{s \lambda^{n}}{1-s \lambda} b\left(x_{1}, x_{0}\right) .
\end{aligned}
$$

As $\lambda \in\left[0, \frac{1}{s}\right)$ and $s>1$, it follows from the above inequality that

$$
\lim _{n, m \rightarrow \infty} b\left(x_{n}, x_{m}\right)=0
$$

Therefore, $\left\{x_{n}\right\}$ is a Cauchy sequence in the complete $b$-partial metric space $X$

Step3. We now prove that $S$ has a fixed point.

Since $\left\{x_{n}\right\}$ is a Cauchy sequence in the complete $b$-partial metric space $X$ and by completeness of $X$, then there exists $x^{*} \in X$ such that

$$
\lim _{n, m \rightarrow \infty} b\left(x_{n}, x^{*}\right)=\lim _{n, m \rightarrow \infty} b\left(x_{n}, x_{m}\right)=b\left(x^{*}, x^{*}\right) .
$$


We will show that $x^{*}$ is a fixed point of $S$. For any $n \in \mathbb{N}$, we have

$$
\begin{aligned}
b\left(x^{*}, S x^{*}\right) & \left.\leq s\left[b\left(x^{*}, x_{n+1}\right)+b\left(x_{n+1}, S x^{*}\right)\right]-b\left(x_{n+1}, x_{n+1}\right)\right] \\
& \leq s\left[b\left(x^{*}, x_{n+1}\right)+b\left(S x_{n}, S x^{*}\right)\right] \\
& \leq s b\left(x^{*}, x_{n+1}\right)+s \lambda b\left(x_{n}, x^{*}\right)
\end{aligned}
$$

Using (2.8) in the above inequality, we obtain $b\left(x^{*}, S x^{*}\right)=0$, that is, $S x^{*}=x^{*}$. Thus, $x^{*}$ is a fixed point of $S$.

Step4. Let us show that the fixed point of $S$ is unique.

Let $u, v \in X$ be two distinct fixed points of $S$, that is, $S u=u$ and $S v=v$. It follows from (2.2) that

$$
\begin{aligned}
\psi(b(u, v))= & \psi(b(S u, S v)) \\
\leq & \lambda F\left(\psi\left(\max \left\{b(u, v), b(u, S u), b(v, S v), \frac{b(u, S v)+b(v, S u)}{2}\right\}\right), \varphi(\max \{b(u, v), b(u, S u), b(v, S v)\right. \\
& \left.\left.\left.\frac{b(u, S v)+b(v, S u)}{2}\right\}\right)\right) \\
\leq & \lambda \psi\left(\max \left\{b(u, v), b(u, S u), b(v, S v), \frac{b(u, S v)+b(v, S u)}{2}\right\}\right) \\
= & \lambda \psi\left(\max \left\{b(u, v), b(u, u), b(v, v), \frac{b(u, v)+b(v, u)}{2}\right\}\right) \\
= & \lambda \psi(b(u, v)) \\
< & \psi(b(u, v)) .
\end{aligned}
$$

Which is contraction. Therefore, we must have $b(u, v)=0$, that is, $u=v$. Thus, the fixed point of $S$ is unique.

The continuity of $S$ in Theorem 2.1 can be dropped.

Theorem 2.2. Let $(X, b)$ be a complete b-partial metric space with coefficient $s \geq 1$ and $S$ be Geraghty contraction type mapping on $X$. Assume that $\alpha, \eta: X \times X \rightarrow[0,+\infty)$ are a functions. Suppose that the following conditions hold:

(1) $S$ is $C$-class function.

(2) $S$ is triangular weak $\alpha$-admissible.

(3) There exists $x_{0} \in X$ such that $\alpha\left(x_{0}, S x_{0}\right) \geq \eta\left(x_{0}, S x_{0}\right)$.

(4) If $\left\{x_{n}\right\}$ is a sequence in $X$ such that $\alpha\left(x_{n}, x_{n+1}\right) \geq \eta\left(x_{n}, x_{n+1}\right)$ for all $n \in \mathbb{N}$ and $x_{n} \rightarrow x^{*} \in X$ as $n \rightarrow \infty$, then there exist a subsequence $\left\{x_{n(k)}\right\}$ of $\left\{x_{n}\right\}$ such that $\alpha\left(x_{n(k)}, x^{*}\right) \geq \eta\left(x_{n(k)}, x^{*}\right)$ for all $k \in \mathbb{N}$.

Then $S$ has a unique fixed point. 
Proof. Following the same proof as in Theorem 2.1, we construct the sequence $\left\{x_{n}\right\}$ be defining $x_{n+1}=S x_{n}$ for all $n \in \mathbb{N}$ converging to $x^{*} \in X$ such that $\alpha\left(x_{n}, x_{n+1}\right) \geq \eta\left(x_{n}, x_{n+1}\right)$ for all $n \in \mathbb{N}$. By condition (5), there exist a subsequence $\left\{x_{n(k)}\right\}$ of $\left\{x_{n}\right\}$ such that $\alpha\left(x_{n(k)}, x^{*}\right) \geq \eta\left(x_{n(k)}, x^{*}\right)$ for all $k \in \mathbb{N}$.

Therefore,

$$
\begin{aligned}
\psi\left(b\left(x_{n(k)+1}, T x^{*}\right)\right) & =\psi\left(d\left(S x_{n(k)}, T x^{*}\right)\right) \\
& \leq \lambda F\left(\psi\left(M\left(x_{n(k)}, x^{*}\right), \varphi\left(M\left(x_{n(k)}, x^{*}\right)\right)\right)\right. \\
& \leq F\left(\psi\left(M\left(x_{n(k)}, x^{*}\right)\right)\right)
\end{aligned}
$$

for all $n \in \mathbb{N}$.

Now,

$$
\begin{aligned}
M\left(x_{n(k)}, x^{*}\right)= & \max \left\{b\left(x_{n}, x^{*}\right), b\left(x_{n(k)}, S x_{n(k)}\right), b\left(x^{*}, S x^{*}\right),\right. \\
& \left.\frac{b\left(x_{n(k)}, S x^{*}\right)+b\left(x^{*}, S x_{n(k)}\right)}{2}\right\}, \\
= & \max \left\{b\left(x_{n(k)}, x^{*}\right), b\left(x_{n(k)}, x_{n(k)+1}\right), b\left(x^{*}, x^{*}\right),\right. \\
& \left.\frac{b\left(x_{n(k)}, x^{*}\right)+b\left(x^{*}, S x_{n(k)}\right)}{2}\right\}, \\
= & \left.\max \left\{d\left(x_{n(k)}, x^{*}\right), d\left(x_{n(k)}, x_{n(k)+1}\right)\right)\right\} .
\end{aligned}
$$

By taking $n \rightarrow \infty$ in (2.9) and using (2.7), we obtain

$$
\psi\left(b\left(x^{*}, S x^{*}\right)\right) \leq \lambda F\left(\psi\left(b\left(x^{*}, S x^{*}\right)\right), \phi\left(b\left(x^{*}, S x^{*}\right)\right)\right),
$$

which implies that $b\left(x^{*}, S x^{*}\right)=0$, that is, $S x^{*}=x^{*}$.

Now, we use Theorem 2.1 and Theorem 2.2 to present many fixed point results:

Corollary 2.1. Let $(X, b)$ be a complete $b$-partial metric space with coefficient $s \geq 1$ and $S$ be mapping on $X$. Assume that $\alpha: X \times X \rightarrow[0,+\infty)$ is a function. Also, suppose that the following conditions hold:

(1) For all $x, y \in X$ with $\alpha(x, y) \geq 1)$, we have $\psi(b(S x, S y)) \leq \lambda F(\psi(b(x, y)), \varphi(b(x, y))$.

(2) $S$ is generalized $C$-class function.

(3) $S$ is a triangular weak $\alpha$-admissible.

(4) There exists $x_{0} \in X$ such that $\alpha\left(x_{0}, S x_{0}\right) \geq 1$.

(5) $S$ is $\alpha, \eta$-continuous mappings.

Then $S$ has a unique fixed point.

Proof. Follows the same proof of the Theorem 2.1 by defining $\eta: X \times X \rightarrow \mathbb{R}$ via $\eta(x, y)=1$.

Corollary 2.2. Let $(X, b)$ be a complete $b$-partial metric space with coefficient $s \geq 1$ and $S$ be mapping on $X$. Assume that $\alpha: X \times X \rightarrow[0,+\infty)$ is a function. Also, suppose that the following conditions hold: 
(1) For all $x, y \in X$ with $\alpha(x, y) \geq 1$, we have $\psi(b(S x, S y)) \leq \lambda F(\psi(b(x, y)), \varphi(b(x, y))$.

(2) $S$ is generalized $C$-class function.

(3) $S$ is a triangular $\alpha$-admissible.

(4) There exists $x_{0} \in X$ such that $\alpha\left(x_{0}, S x_{0}\right) \geq 1$.

(5) If $\left\{x_{n}\right\}$ is a sequence in $X$ such that $\alpha\left(x_{n}, x_{n+1}\right) \geq 1$ for all $n \in \mathbb{N}$ and $x_{n} \rightarrow x^{*} \in X$ as $n \rightarrow \infty$, then there exist a subsequence $\left\{x_{n(k)}\right\}$ of $\left\{x_{n}\right\}$ such that $\alpha\left(x_{n(k)}, x^{*}\right) \geq 1$ for all $k \in \mathbb{N}$.

Then $S$ has a unique fixed point.

Proof. Follows the same proof of the Theorem 2.2 by defining $\eta: X \times X \rightarrow \mathbb{R}$ via $\eta(x, y)=1$.

Let $\beta:[0,+\infty) \rightarrow[0,1)$ be a continuous function. Define $S:[0, \infty) \times[0, \infty) \rightarrow[0, \infty)$ via $F(s, t)=s \beta(t)$. Then $F \in \mathcal{C}$. By Theorem 2.1 and Theorem 2.2, we have the following results:

Corollary 2.3. Let $(X, b)$ be a complete $b$-partial metric space with coefficient $s \geq 1$ and $S$ be mapping on $X$. Assume that $\alpha, \eta: X \times X \rightarrow[0,+\infty)$ are a functions. Suppose there exist $\psi \in \Psi$ and a continuous function $\beta:[0,+\infty) \rightarrow[0,1)$ such that for all $x, y \in X$ with $\alpha(x, y) \geq \eta(x, y)$, we have

$$
\psi(b(S x, S y)) \leq \lambda F(\beta(\psi(b(x, y))), \varphi(b(x, y)) .
$$

Also, suppose that the following conditions hold:

(1) $S$ is generalized $C$-class function.

(2) $S$ is a triangular weak $\alpha$-admissible.

(3) There exists $x_{0} \in X$ such that $\alpha\left(x_{0}, S x_{0}\right) \geq 1$.

(4) $S$ is $\alpha, \eta$-continuous mappings.

Then $S$ has a unique fixed point.

Corollary 2.4. Let $(X, b)$ be a complete $b$-partial metric space with coefficient $s \geq 1$ and $S$ be mapping on $X$. Assume that $\alpha, \eta: X \times X \rightarrow[0,+\infty)$ are a functions. Suppose there exist $\psi \in \Psi$ and a continuous function $\beta:[0,+\infty) \rightarrow[0,1)$ such that for all $x, y \in X$ with $\alpha(x, y) \geq \eta(x, y)$, we have

$$
\psi(b(S x, S y)) \leq \lambda F(\beta(\psi(b(x, y))), \varphi(b(x, y)) .
$$

Also, suppose that the following conditions hold:

(1) $S$ is generalized $C$-class function.

(2) $S$ is a triangular weak $\alpha$-admissible.

(3) There exists $x_{0} \in X$ such that $\alpha\left(x_{0}, S x_{0}\right) \geq \eta\left(x_{0}, S x_{0}\right)$.

(4) If $\left\{x_{n}\right\}$ is a sequence in $X$ such that $\alpha\left(x_{n}, x_{n+1}\right) \geq \eta\left(x_{n}, x_{n+1}\right)$ for all $n \in \mathbb{N}$ and $x_{n} \rightarrow x^{*} \in X$ as $n \rightarrow \infty$, then there exist a subsequence $\left\{x_{n(k)}\right\}$ of $\left\{x_{n}\right\}$ such that $\alpha\left(x_{n(k)}, x^{*}\right) \geq \eta\left(x_{n(k)}, x^{*}\right)$ for all $k \in \mathbb{N}$. 
Then $S$ has a unique fixed point.

Example 2.2. Let $X=[0,1]$ and $b: X \times X \rightarrow \mathbb{R}$ define by $b(x, y)=|x-y|^{2}$ for all $x, y \in X$. Define $\psi, \phi:[0, \infty) \rightarrow[0, \infty)$ by $\psi(t)=t$ and $\phi(t)=\frac{4}{25} t$. Define the mapping $S: \mathbb{R} \rightarrow \mathbb{R}$ by $S x=\frac{\ln x}{5}$. Also, we define the functions $\alpha, \eta: X \times X \rightarrow[0, \infty)$ by

$$
\alpha(x, y)=\left\{\begin{array}{ll}
e^{x+y} & \text { if } x, y \in[0,1], \\
0 & \text { if otherwise }
\end{array} \quad \eta(x, y)= \begin{cases}1 & \text { if } x, y \in[0,1] \\
0 & \text { if otherwise }\end{cases}\right.
$$

and $F(r, t)=r-t$ for all $r, t, x, y \in X$.

Firstly, It is easy to see that $(X, b)$ is a complete partial b-metric space with $s=3$.

Then $S$ is a triangular weak $\alpha$-admissible with respect to $\eta$. Indeed, if $\alpha(x, S x) \geq \eta(x, S x)$, then $\alpha\left(S x, S^{2} x\right) \geq \eta\left(S x, S^{2} x\right)$, So $\alpha(x, \ln x+1)=e^{x+\ln x}>1=\eta(x, \ln x)$, then $\alpha(\ln x, \ln (\ln x))=e^{\ln x+\ln (\ln x)} \geq$ $e=\eta(\ln x, \ln (\ln x))$.So $x \geq 0$ and hence $S x \leq 0$. Therefore, $\alpha(x, S x) \geq \eta(x, S x)$.

We will prove that $S$ is a generalized $C$-class function. Since $\alpha(x, S x) \geq \eta(x, S x)$. Then we have $x, y \in[0,1]$ and then

$$
\begin{aligned}
\psi(d(S x, S y)) & =\left|\frac{\ln x}{5}-\frac{\ln y}{5}\right|^{2} \\
& =\frac{1}{25}|\ln x-\ln y|^{2} \\
& =\frac{1}{25} b(x, y) \\
& \leq \frac{1}{25} M(x, y) \\
& =M(x, y)-\frac{24}{25} M(x, y) \\
& =\psi(M(x, y))-\phi(M(x, y)) \\
& =F(\psi(M(x, y)), \phi(M(x, y))) .
\end{aligned}
$$

Then $S$ is a generalized $C$-class function and all assumptions of Corollary 2.1 are satisfied. Hence $S$ has a unique fixed point.

\section{Applications}

In this section, we apply our results to construct an application on Lebesgue-integrable. Denote by $\Gamma$ the set of all functions $\gamma: \mathbb{R}^{+} \rightarrow \mathbb{R}^{+}$satisfying the following conditions: 
(1) $\gamma$ is Lebesgue-integrable on each compact of $\mathbb{R}^{+}$;

(2) For each $\epsilon>0$, we have

$$
\int_{0}^{\epsilon} \gamma(z) d z>0
$$

Theorem 3.1. Let $(X, b)$ be a complete $b$-partial metric space with coefficient $s \geq 1$ and $S$ be Geraghty contraction type mappings on $X$. Also, let $F \in \mathcal{C}$ and $\gamma_{1}, \gamma_{2} \in \Gamma$. Assume that $\alpha, \eta: X \times X \rightarrow[0, \infty)$ be two functions such for all $x, y \in X$ with $\alpha(x, y) \geq \eta(x, y)$, we have

$$
\begin{aligned}
\left.\int_{0}^{d(S x, T y)} \gamma_{1}(z)\right) d z \leq & F\left(\int_{0}^{\max \left\{d(x, y), d(x, S x), d(T x, T y), \frac{b(x, S y)+b(y, S x)}{2}\right\}} \gamma_{1}(z) d z\right. \\
& \left.\int_{0}^{\max \left\{d(x, y), d(x, S x), d(T x, T y), \frac{b(x, S y)+b(y, S x)}{2}\right\}} \gamma_{2}(z) d z\right) .
\end{aligned}
$$

Also, suppose the following hypotheses:

(1) $S$ is generalized $C$-class function.

(2) $S$ is a triangular weak $\alpha$-admissible.

(3) There exists $x_{0} \in X$ such that $\alpha\left(x_{0}, S x_{0}\right) \geq 1$.

(4) $S$ is $\alpha, \eta$-continuous mappings.

Then $S$ has a unique fixed point.

Proof. Define the functions $\psi, \varphi: \mathbb{R}^{+} \rightarrow \mathbb{R}^{+}$via $\left.\psi(t)=\int_{0}^{t} \gamma_{1}(z)\right) d z$ and $\left.\varphi(t)=\int_{0}^{t} \gamma_{2}(z)\right) d z$. Noting that $\psi$ is an altering distance function and $\varphi \in \Phi$. So $S$ is triangular weak $\alpha$-admissible with respect to $\eta$. So $S$ satisfies all the hypotheses of theorem 2.1. Therefore $S$ has a fixed point.

Theorem 3.2. Let $(X, b)$ be a complete b-partial metric space with coefficient $s \geq 1$ and $S$ be Geraghty contraction type mappings on $X$. Also, let $F \in \mathcal{C}$ and $\gamma_{1}, \gamma_{2} \in \Gamma$. Assume that $\alpha, \eta: X \times X \rightarrow[0, \infty)$ be two functions such for all $x, y \in X$ with $\alpha(x, y) \geq \eta(x, y)$, we have

$$
\begin{aligned}
\left.\int_{0}^{d(S x, T y)} \gamma_{1}(z)\right) d z \leq & F\left(\int_{0}^{\max \left\{d(x, y), d(x, S x), d(T x, T y), \frac{b(x, S y)+b(y, S x)}{2}\right\}} \gamma_{1}(z) d z\right. \\
& \left.\int_{0}^{\max \left\{d(x, y), d(x, S x), d(T x, T y), \frac{b(x, S y)+b(y, S x)}{2}\right\}} \gamma_{2}(z) d z\right) .
\end{aligned}
$$

Also, suppose the following hypotheses:

(1) $S$ is generalized $C$-class function.

(2) $S$ is a triangular weak $\alpha$-admissible.

(3) There exists $x_{0} \in X$ such that $\alpha\left(x_{0}, S x_{0}\right) \geq 1$. 
(4) If $\left\{x_{n}\right\}$ is a sequence in $X$ such that $\alpha\left(x_{n}, x_{n+1}\right) \geq \eta\left(x_{n}, x_{n+1}\right)$ for all $n \in \mathbb{N}$ and $x_{n} \rightarrow x^{*} \in X$ as $n \rightarrow \infty$, then there exist a subsequence $\left\{x_{n(k)}\right\}$ of $\left\{x_{n}\right\}$ such that $\alpha\left(x_{n(k)}, x^{*}\right) \geq \eta\left(x_{n(k)}, x^{*}\right)$ for all $k \in \mathbb{N}$.

Then $S$ has a unique fixed point.

Proof. Follow from Theorem 2.2 by defining $\left.\psi(t)=\int_{o}^{t} \gamma_{1}(z)\right) d z$ and $\left.\varphi(t)=\int_{o}^{t} \gamma_{2}(z)\right) d z$. Noting that the mapping $S$ satisfies all the hypotheses of theorem 2.2 .

\section{Acknowledgement}

The authors would like to acknowledge the grant: UKM Grant DIP-2014-034 and Ministry of Education, Malaysia grant FRGS/1/2014/ST06/UKM/01/1 for financial support.

\section{REFERENCES}

[1] T. Abdeljawad, Meir-Keeler $\alpha$-contractive fixed and common fixed point theorems, Fixed Point Theory Appl., 2013 (2013), Art. ID 19.

[2] A. Aghajani, M. Abbas, J.R. Roshan, Common fixed point of generalized weak contractive mappings in partially ordered b-metric spaces, Mathematica Slovaka, (2013).

[3] S. Alizadeh, F. Moradlou, P. Salimi, Some fixed point results for $(\alpha, \beta)-(\psi, \phi)$-contractive mappings, Filomat, 28 (2014), 635-647.

[4] A. H. Ansari, Note on $\varphi-\psi-$ contractive type mappings and related fixed point, The 2nd Regional Conference on Mathematics and Applications, (2014), 377-380.

[5] A.H Ansari, W. Shatanawi, A. kurdi, G. Maniu, Best promixity points in complete metric spaces with $(P)-$ property via C-class fuctions, J. Math. Anal., 7 (2016), 54-67.

[6] A. H. Ansari, J. Kaewcharoen, $C$-class functions and fixed point theorems for generalized $\alpha-\eta-\psi-\varphi-F$-contraction type mappings in $\alpha$ - $\eta$-complete metric spaces, J. Nonlinear Sci. Appl., 9 (2016), 4177-4190.

[7] I.A. Bakhtin, The contraction mapping principle in almost metric spaces, Funct. Anal., 30 (1989), 26-37.

[8] S. Banach, Sur Les opérations dans les ensembles abstraits et leur application aux équations intégrals, Fund. Math, 3 (1922), 133-181.

[9] A. Branciari, A fixed point theorem of Banach-Caccioppoli type on a class of generalized metric spaces, Publ. Math. Debrecen. 57 (2000), 31-37.

[10] S. Czerwik, Contraction mappings in b-metric spaces, Acta Math. Inform. Univ. Ostrav., 1 (1993), 5-11.

[11] S. Czerwik, Nonlinear set-valued contraction mappings in b-metric spaces, Atti Sem. Mat. Univ. Modena, 46 (1998), 263-276.

[12] P. Das, A fixed point theorem in a generalized metric space, Soochow J. Math., 33 (2007) 33-39.

[13] H. Isik, A. H. Ansari,S. Chandok, Common fixed points for $(\psi, f, \alpha, \beta)$-weakly contractive mappings in generalized matric space via new functions, Gazi Univ. J. Sci., 4 (2015),703-708.

[14] N. Hussain, P. Salimi and A. Latif, Fixed point results for single and set-valued a $\alpha-e t a-\psi$-contractive mappings, Fixed Point Theory Appl., 2013 (2013), Art. ID 212. 
[15] N. Hussain, M. A. Kutbi, P. Salimi, Fixed point theory in $\alpha$-complete metric spaces with applications, Abstr. Appl. Anal., 2014 (2014), Article ID 280817.

[16] E. Karapinar, B. Samet, Generalized $\alpha-\psi$-contractive type mappings and related fixed point theorems with applications, Abstr. Appl. Anal., (2012), Article ID 793486.

[17] E. Karapinar, P. Kumam and P. Salimi, On $\alpha-\psi-$ Meir-Keeler contractive mappings, Fixed Point Theory Appl., 2013 (2013), Art. ID 94.

[18] E. Karapinar, $\alpha-\psi$-Geraghty contraction type mappings and some relatead fixed point results, Filomat, 28 (2014), $37-48$.

[19] M. S. Khan, A fixed point theorem for metric spaces, Rend. Inst. Math. Univ. Trieste., 8 (1976), 69-72.

[20] M. S. Khan, M. Swaleh, and S. Sessa, Fixed point theorems by altering distances between the points, Bull. Aust. Math. Soc., 30 (1984), 1-9.

[21] S.G Matthews, Partial metric topology, Proc. 8th Summer Conference on General Topology and Application. Ann. New York Acad. Sci., 728 (1994), 183-197.

[22] D. K. Patel, Th. Abdeljawad, D. Gopal, Common fixed points of generalized Meir-Keeler $\alpha$-contractions, Fixed Point Theory Appl., 2013 (2013), Art. ID 260.

[23] H. Qawaqneh, M. S. M. Noorani, W. Shatanawi, H. Alsamir, Common fixed points for pairs of triangular $(\alpha)-$ admissible mappings, J. Nonlinear Sci. Appl., 10 (2017), 6192-6204.

[24] H. Qawaqneh, M. S. M. Noorani, W. Shatanawi, K. Abodayeh, H. Alsamir, Fixed point for mappings under contractive condition based on simulation functions and cyclic $(\alpha, \beta)$-admissibility, J. Math. Anal., 9 (2018), 38-51.

[25] H. Qawaqneh, M. S. M. Noorani, W. Shatanawi, Fixed Point Results for Geraghty Type Generalized $F$-contraction for Weak alpha-admissible Mapping in Metric-like Spaces, Eur. J. Pure Appl. Math., 11 (2018), 702-716.

[26] H. Qawaqneh, M.S.M. Noorani, W. Shatanawi, Common Fixed Point Theorems for Generalized Geraghty $(\alpha, \psi, \phi)$-Quasi Contraction Type Mapping in Partially Ordered Metric-like Spaces, Axioms, 7 (2018), Art. ID 74.

[27] H. Qawaqneh, M.S.M. Noorani, W. Shatanawi, Fixed Point Theorems for $(\alpha, k, \theta)$-Contractive Multi-Valued Mapping in b-Metric Space and Applications, Int. J. Math. Comput. Sci., 14 (2018), 263-283.

[28] H. Qawaqneh, M.S.M. Noorani, W. Shatanawi, H. Alsamir, Some Fixed Point Results for the Cyclic $(\alpha, \beta)-(k, \theta)-$ MultiValued Mappings in Metric Space, International Conference on Fundamental and Applied Sciences (ICFAS2018), 2018.

[29] J. R. Roshan, V. Parvaneh, S. Sedghi, N. Shobkolaei, W. Shatanawi, Common fixed points of almost generalized $(\psi, \varphi)_{s^{-}}$ contractive mappings in ordered b-metric spaces, Fixed Point Theory Appl., 2013 (2013), Art. ID 159.

[30] P. Salimi, A. Latif and N. Hussain, Modified a $\alpha-\psi$-contractive mappings with applications, Fixed Point Theory Appl. 2013 (2013), Art. ID 151.

[31] B. Samet, C. Vetro, P. Vetro, Fixed point theorems for a $\alpha-\psi$-contractive type mappings, Nonlinear Anal., Theory Methods Appl., 75 (2012), 2154-2165.

[32] W. Sintunavarat, Nonlinear integral equations with new admissibility types in $b$-metric spaces, J. Fixed Point Theory Appl., 18 (2016), 397-416.

[33] W. Shatanawi and M. Postolache, common fixed point results for mappings under nonlinear contraction of cyclic form in ordered metric spaces, Fixed Point Theory Appl., 2013 (2013), Art. ID 60.

[34] W. Shatanawi, M. Noorani, H. Alsamir and A. Bataihah, Fixed and common fixed point theorems in partially ordered quasi-metric spaces, J. Math. Computer Sci., 16 (2016), 516-528.

[35] S. Shukla, Partial b-metric spaces and fixed point theorems, Mediterr. J. Math., 11(2014), 703-711. 